\title{
Side-to-side asymmetries in landing mechanics from a drop vertical jump test are not related to asymmetries in knee joint laxity following anterior cruciate ligament reconstruction
}

\author{
Christophe A. G. Meyer ${ }^{1} \cdot$ Paul Gette $^{1} \cdot$ Caroline Mouton $^{2} \cdot$ Romain Seil $^{1,2}$ • \\ Daniel Theisen ${ }^{1}$
}

Received: 7 March 2017 / Accepted: 12 July 2017 / Published online: 15 July 2017

(c) The Author(s) 2017. This article is an open access publication

\begin{abstract}
Purpose Asymmetries in knee joint biomechanics and increased knee joint laxity in patients following anterior cruciate ligament reconstruction (ACLR) are considered risk factors for re-tear or early onset of osteoarthritis. Nevertheless, the relationship between these factors has not been established. The aim of the study was to compare knee mechanics during landing from a bilateral drop vertical jump in patients following ACLR and control participants and to study the relationship between side-to-side asymmetries in landing mechanics and knee joint laxity.

Methods Seventeen patients following ACLR were evaluated and compared to 28 healthy controls. Knee sagittal and frontal plane kinematics and kinetics were evaluated using three-dimensional motion capture $(200 \mathrm{~Hz})$ and two synchronized force platforms $(1000 \mathrm{~Hz})$. Static anterior and internal rotation knee laxities were measured for both groups and legs using dedicated arthrometers. Group and leg differences were investigated using a mixed model analysis of variance. The relationship between side-to-side differences in sagittal knee power/energy absorption and knee joint laxities was evaluated using univariate linear regression.
\end{abstract}

Results A significant group-by-leg interaction $(p=0.010)$ was found for knee sagittal plane energy absorption, with patients having $25 \%$ lower values in their involved

Daniel Theisen

daniel.theisen@lih.lu

1 Sports Medicine Research Laboratory, Department of Population Health, Luxembourg Institute of Health, 76, Rue d'Eich, 1460 Luxembourg, Luxembourg

2 Department of Orthopaedic Surgery, Centre Hospitalier de Luxembourg - Clinique d'Eich, Luxembourg, Luxembourg compared to their non-involved leg $(1.22 \pm 0.39$ vs. $1.62 \pm 0.40 \mathrm{~J} \mathrm{~kg}^{-1}$ ). Furthermore, knee sagittal plane energy absorption was $18 \%$ lower at their involved leg compared to controls $(p=0.018)$. Concomitantly, patients demonstrated a $27 \%$ higher anterior laxity of the involved knee compared to the non-involved knee, with an average side-to-side difference of $1.2 \mathrm{~mm}(p<0.001)$. Laxity of the involved knee was also $30 \%$ higher than that of controls $(p<0.001)$ (leg-by-group interaction: $p=0.002$ ). No relationship was found between sagittal plane energy absorption and knee laxity.

Conclusions Nine months following surgery, ACLR patients were shown to employ a knee unloading strategy of their involved leg during bilateral landing. However, this strategy was unrelated to their increased anterior knee laxity. Side-to-side asymmetries during simple bilateral landing tasks may put ACLR patients at increased risk of second ACL injury or early-onset osteoarthritis development. Detecting and correcting asymmetric landing strategies is highly relevant in the framework of personalized rehabilitation, which calls for complex biomechanical analyses to be applied in clinical routine.

Level of evidence III.

Keywords Knee injury $\cdot$ Knee kinematics $\cdot$ Knee kinetics $\cdot$ Static anterior laxity $\cdot$ Rotational knee laxity · Asymmetrical knee loading

\section{Introduction}

Patients undergoing anterior cruciate ligament reconstruction (ACLR) have an increased risk of re-injury when returning to sport activities, especially in the first two years following surgery [28, 39]. Previous studies have suggested 
that this increased risk of subsequent ipsilateral or contralateral ACL tear might be related to abnormal knee function during dynamic movements $[9,29,30]$. In addition, since abnormal knee biomechanics have been suggested as a contributing factor to knee osteoarthritis development $[2,6,12]$, their assessment is crucial in the evaluation of functional recovery. The current literature highlights landing mechanics evaluation during standardized jump tasks as an interesting screening tool for injury risk. Several studies have reported asymmetric landing strategies among patients following ACLR [4, 27, 29]. Paterno et al. [29] reported increased knee range of motion in the frontal plane as well as increased knee flexion moment at initial contact during landing from a drop vertical jump at the injured compared to the non-injured leg. These alterations were suggested as predictive factors of subsequent ACL injury in patients after ACLR. Similarly, Oberländer et al. [26] found that patients following ACLR had persistent abnormal knee biomechanics at the injured leg during a single-leg hop test, which may place them at higher risk of knee osteoarthritis development. The observed asymmetrical biomechanical pattern has often been proposed to arise from quadriceps strength deficits in the involved leg [16, 31], patients with the greatest deficits showing the largest asymmetries in sagittal knee biomechanics. The link between muscle strength deficits and abnormal biomechanics has led the scientific community to investigate joint energetics, as represented by the physical work performed by the muscles. Indeed, the integration of the joint mechanical power curve over time, i.e. work, is an indirect measure of muscle work giving insights into the movement strategy [40]. Nonetheless, few studies have investigated mechanical work during landing in the context of ACLR.

Another important aspect related to knee function following ACLR is static knee joint laxity [1, 5, 14, 19]. In spite of surgery seeking to restore normal knee laxity, greater anteroposterior, but not rotational, knee joint laxity has been shown in patients following ACLR [19]. Additionally, increased static knee joint laxity has been associated with greater risk of primary ACL injury $[23,36]$.

Static knee joint laxity measures represent an analytical evaluation of the passive knee joint characteristics. It is currently not known in how far the latter impact knee joint control under dynamic conditions. Indeed, the relationship between knee laxity and dynamic knee biomechanics has not yet been analysed in the context of patients following ACLR. The existence of such relationship would have implications for both surgical and rehabilitative interventions. To the authors' knowledge, only two research groups have investigated this topic in a healthy population [33-35]. Shultz et al. [33] found that increased knee joint laxity was associated with greater knee valgus angles and internal knee varus moments during landing. Furthermore, increased anterior knee joint laxity was associated with greater knee energy absorption, but only in females [34]. Torry et al. [35] found that anterior knee laxity was related to peak anterior tibial translation during stiff drop landings. How far these relationships apply to ACLR patients remains to be determined.

The aim of this study was therefore to investigate knee landing mechanics during a drop vertical jump task in patients following ACLR and in control participants. It was hypothesized that (1) ACLR patients would demonstrate greater side-to-side differences in knee landing biomechanics than controls, (2) ACLR patients would display greater side-to-side differences in knee joint laxity, and finally (3) asymmetries in knee landing mechanics would be related to asymmetries in knee joint laxity.

\section{Materials and methods}

Thirty-one patients consulting at the orthopaedic department of our clinic between February and December 2015 met the inclusion criteria: age range $15-35$ years, unilateral ACL injury, no other previous lower limb injuries that could affect jump performance, minimum of 6 months postsurgery, full knee extension, minimum of $140^{\circ}$ knee flexion and medically cleared to perform the protocol tests. Eventually, 17 of these patients agreed to take part in our study. All had participated in sports before surgery (Table 1) and had an average Knee injury and Osteoarthritis Outcome Score (KOOS) for sports and recreation of $83( \pm 15)$ (selfadministered questionnaire) at the time of testing.

A control group including twenty-eight healthy, active, age-matched volunteers was selected. Their recruitment was based on questionnaires to exclude any previous knee injury, musculoskeletal and neurological disorders and any impairment interfering with the task. Knee pain during task execution was monitored and used as an exclusion criterion for all participants.

\section{Drop vertical jump test}

Participants were familiarized with the experimental procedures during a separate test session. The protocol consisted in executing several drop vertical jumps (DVJs) during which three-dimensional impact forces and lower limb movements were measured. Jump tasks were preceded by a 10-min warm-up run on a treadmill at a self-selected pace. Participants wore tight clothing and standardized footwear during testing.

DVJs were performed from a height of $0.4 \mathrm{~m}$, with arms akimbo and feet hip width apart. Participants were instructed to drop off a box, land with their feet on separate force platforms and perform a maximal vertical jump 
Table 1 Demographics of study participants

\begin{tabular}{|c|c|c|}
\hline & Controls $(n=28)$ & Patients $(n=17)$ \\
\hline Age (years) & $25.4( \pm 4.1)$ & $24.5( \pm 6.8)$ \\
\hline BMI $\left(\mathrm{kg} \mathrm{m}^{-2}\right)$ & $22.4( \pm 1.9)$ & $23.1( \pm 2.4)$ \\
\hline Gender (females/males) & $14 \mathrm{~F} / 14 \mathrm{M}$ & $5 \mathrm{~F} / 12 \mathrm{M}$ \\
\hline Follow-up time (months) & NA & $8.9( \pm 1.3)$ \\
\hline ACL injury mechanism & NA & 4 contact/13 non-contact \\
\hline Graft type & NA & $11 \mathrm{HS} / 6$ BPTВ \\
\hline Associated lesions ${ }^{\mathrm{a}}$ & NA & Yes $(n=11) / \mathrm{No}(n=6)$ \\
\hline Sports participation (h/week) & $5( \pm 2)$ & $8( \pm 4)$ \\
\hline Sport activity level ${ }^{\mathrm{b}}$ & $\begin{array}{l}\text { I }(n=10) ; \mathrm{II}(n=7) ; \mathrm{III} \\
\quad(n=11)\end{array}$ & $\mathrm{I}(n=13) ; \mathrm{II}(n=2) ; \mathrm{III}(n=2)$ \\
\hline
\end{tabular}

Data are presented as means $( \pm \mathrm{SD})$

$H S$ hamstring graft, $B P T B$ bone-patellar tendon-bone graft (note: three patients underwent extra-articular lateral tenodesis)

${ }^{a}$ Associated lesions were medial meniscal tear $(n=1)$, lateral meniscal tear $(n=4)$ or both $(n=6)$

${ }^{\mathrm{b}}$ Sport activity level before injury: level I refers to sports with jumping, pivoting, hard cutting actions (e.g. football, basketball, handball), level II refers to moderate pivoting, jumping and cutting actions (e.g. skiing, tennis, volleyball), and level III refers to sports with no pivoting actions (jogging, running) [13] after the first landing (Fig. 1). Participants performed several DVJs until three valid trials were recorded. Trials were considered invalid when participants jumped from the box instead of dropping or lost their balance, when their hands did not remain on the waist or when the feet did not touch separate force platforms.

After recording height and mass, participants were fitted with 34 active markers according to a 6-degrees-offreedom six-segment lower limb model including feet, shanks and thighs. A single experienced assessor performed marker positioning to minimize placement errors. Tracking markers $(n=24)$ comprised rigid clusters of four markers applied on the thighs and shanks, as well as four markers attached on the shoes. Prior to dynamic testing, anatomical calibration of each segment and neutral limb alignment were defined using additional anatomical markers $(n=10)$ applied on the malleoli, femoral condyles and greater trochanter of each limb (Fig. 2). Three-dimensional marker trajectories were recorded using four CODA CX1 optoelectronic motion capture units (Charnwood Dynamics Ltd, Leicestershire, UK) sampling at $200 \mathrm{~Hz}$. Ground reaction forces for each leg were synchronously collected at $1000 \mathrm{~Hz}$ using two separate force platforms (Arsalis $800 \times 500$; Arsalis SPRL; Louvain-la-Neuve, Belgium).

\section{Biomechanical data processing}

Data processing was performed using Visual 3D (v5.02.24; C-Motion, Inc., Germantown, MD) and custom-made MATLAB program (MATLAB R2014a, The MathWorks ${ }^{\circledR}$, Natick, MA, USA). Initial contact and take-off events were determined based on a $10 \mathrm{~N}$ threshold from the vertical ground reaction force vector. Kinematic and kinetic signals were low-pass-filtered using the same fourth-order Butterworth filter with a $6 \mathrm{~Hz}$ cut-off frequency [18]. Knee joint angles were calculated using a Cardan XYZ rotation sequence. Net external knee joint moments were computed using standard inverse dynamics. All data were time-normalized from 0 to $100 \%$ with respect to the contact phase of the landing. Biomechanical variables of interest were determined only during the eccentric landing phase defined as initial contact to maximal knee flexion angle.

Biomechanical variables were averaged from the three valid trials and included knee flexion and valgus angles at initial contact, peak knee flexion and valgus angles, net peak knee flexion, valgus and varus moments, and sagittal peak knee power absorption. Sagittal knee power was computed at each time point by multiplying the angular velocity of the sagittal knee angle with the sagittal knee joint moment [10]. Hence, the work done by the knee extensors during the phase of landing, i.e. energy absorption by the knee extensor muscles, was calculated by integrating the joint power curve over the time of the negative phase. All kinetic data were normalized to body mass.

\section{Knee joint laxity}

All participants underwent anterior and internal rotation knee laxity evaluations on both legs using previously described procedures yielding a standard error of measurement of less than $10 \%$ [22] (Fig. 3). In patients, the noninjured knee was tested first, while the first knee tested in controls was randomly chosen. Anterior knee laxity measures were performed using the GNRB $\odot$ arthrometer $(\mathrm{GeN}$ ouRob company, France) allowing to perform a standardized Lachman test using a calibrated motor. Participants 
$\begin{array}{lll}\text { Starting position } \quad \text { Initial contact } \quad \text { Maximum knee flexion } & \text { Take-off }\end{array}$
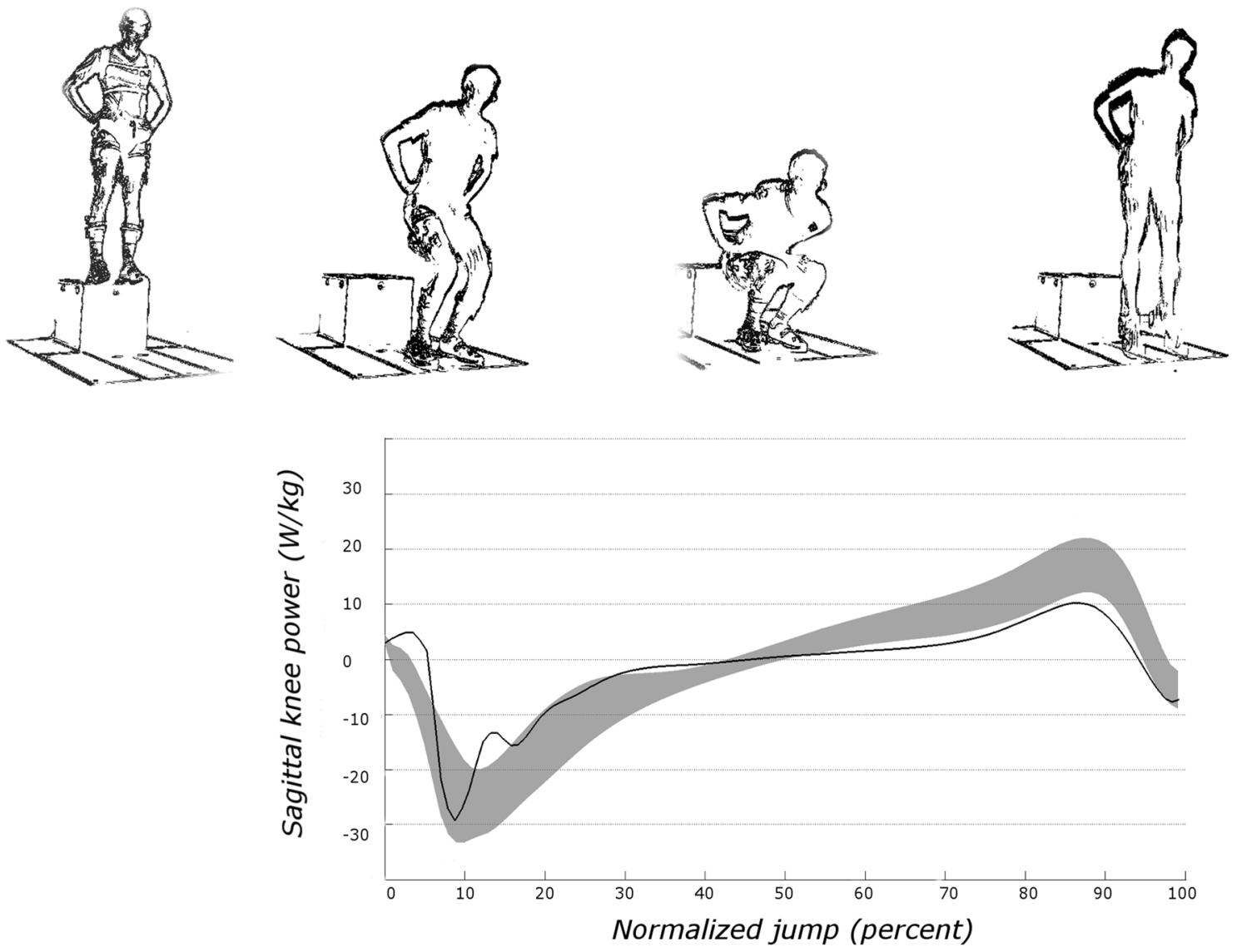

Fig. 1 Schematic representation of the drop vertical jump test. In the lower part, a typical graphical representation of sagittal plane knee power is represented. The grey zone represents average $\pm 1 \mathrm{SD}$ of the control group

were supine with the tested leg on the device and the non-tested leg resting on the examination table. The tested knee was flexed at $20^{\circ}$ and positioned with the femoral intercondylar line at the edge of the leg support. The knee was immobilized via a patella shell and positioned so as to ensure central alignment with the tibial axis. The foot was tightened on a foot support. Maximal anterior tibial displacement (ATD200) was measured by applying a progressive force up to $200 \mathrm{~N}$ via a plateau fixed on a hydraulic cylinder. Displacement was recorded to the nearest $0.1 \mathrm{~mm}$ by a sensor placed perpendicularly to the tibia on the tibial tuberosity. The average of the last two of three successive ATD200 measurements was taken for further calculations. Rotational knee laxity was evaluated in the internal direction using the rotameter device to reproduce a standardized dial test [21]. Patients were laying prone on an examination table with their thighs fixed, knee flexed at $30^{\circ}$ and the foot immobilized in a ski boot, itself affixed to a manual handle bar. The latter was used to apply a progressive torque up to $5 \mathrm{Nm}$, and the resulting rotation (IR5) was measured via an inclinometer of an accuracy of $0.01^{\circ}$. The average of the last two of four successive IR5 measurements was taken for further data processing.

All procedures were approved by the National Research Ethics Committee (CNER, Luxembourg, approval $\left.\mathrm{n}^{\circ} 201101 / 05\right)$. Written informed consent was obtained prior to participation.

\section{Statistical analysis}

Based on preliminary analysis of 10 patients, we expected an effect size of 1.0 for the side-to-side difference in peak knee power and energy absorption during landing from a drop jump, our main variables of interest. Thus, given a power of 0.8 and an alpha level of $0.05,16$ patients were required to detect significant differences between the two legs.

For testing group and leg differences, a distinction was made between the involved (operated) $\left(\mathrm{ACLR}_{\text {inv }}\right)$ and the non-involved leg $\left(\mathrm{ACLR}_{n \text {-inv }}\right)$ in patients, while for controls the involved $\left(\mathrm{CON}_{\text {inv }}\right)$ and non-involved legs $\left(\mathrm{CON}_{n \text {-inv }}\right)$ were randomly chosen [38]. Thus, biomechanical variables were compared using a mixed model analysis of variance 


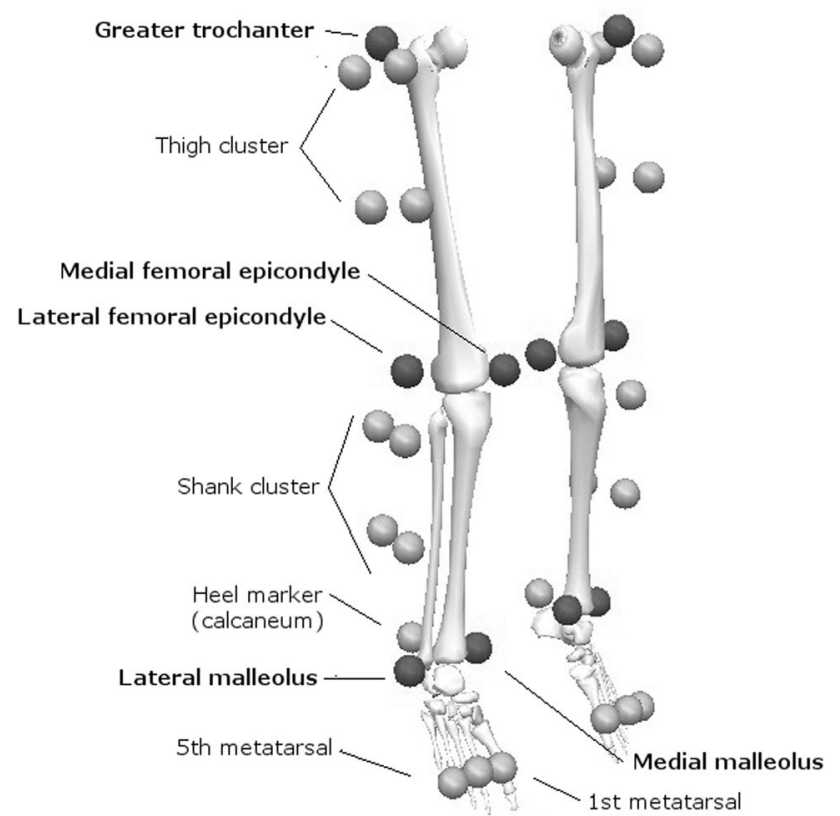

Fig. 2 Marker positions defining lower limb kinematic model. Markers indicated in bold are anatomical markers that were used during static calibration only

[group (2) $\times$ leg (2)]. When a significant group-by-leg interaction was found, a two-tailed post hoc comparison (between limbs and between groups) was carried out. Data are presented as average \pm standard deviation (SD). Statistical significance was set at $p<0.05$. The side-to-side differences, expressed as the difference between the involved and non-involved leg, were determined for the biomechanical variables as well as for the laxity data. To study the relationship between peak knee power/energy absorption and knee laxity, univariate linear regressions were computed. All statistical analyses were performed using SPSS Version 23 (IBM, Houston, TX, USA).

\section{Results}

Table 1 summarizes participants' characteristics. ACLR patients were evaluated at an average of $8.9 \pm 1.3$ months (median 8.6; range 6-11) after surgery.
While no group-by-leg effect was found for peak knee power absorption in the sagittal plane during landing from the DVJ (n.s), a group-by-leg interaction $(p=0.010)$ was found for knee energy absorption (Table 2). Post hoc analysis revealed that $\mathrm{ACLR}_{\text {inv }}$ had $25 \%$ lower knee energy absorption than $\operatorname{ACLR}_{n \text {-inv }}(p<0.001)$, as well as $18 \%$ lower than $\mathrm{CON}_{\text {inv }}(p=0.018)$. In 14 patients, the side-to-side differences $\left(\mathrm{ACLR}_{\text {inv }}-\mathrm{ACLR}_{n \text {-inv }}\right)$ in sagittal plane energy absorption at the knee were outside the $95 \%$ confidence interval of differences found for the control group. These strong asymmetries were negative in 11 patients (69\%), illustrative of an unloading strategy of their involved leg, while they were positive in three patients, showing overloading of the involved leg.

There was a main leg effect for peak knee flexion angle and peak external knee flexion moment, with overall greater values found for the non-involved legs in both groups. ACLR $\mathrm{inv}_{\text {inv }}$ had $17 \%$ lower peak knee flexion moment compared to $\operatorname{ACLR}_{n \text {-inv }}$, while only a $6 \%$ difference was found for $\mathrm{CON}_{\text {inv }}$ and $\mathrm{CON}_{n \text {-inv }}$ Significant main group effects $(p=0.001)$ were found for peak knee valgus and varus moments, which were higher and lower, respectively, in the patient group.

A group-by-leg interaction $(p=0.002)$ was found for ATD200 (Table 2), with a 27\% higher value $(p<0.001)$ for $\mathrm{ACLR}_{\text {inv }}$ compared to $\mathrm{ACLR}_{n \text {-inv, }}$, and a $30 \%$ higher result $(p<0.001)$ compared to both legs of the control group. A group effect was found ( $p=0.002)$ for ATD200 illustrating the overall greater anterior knee laxity in the patient group (pooled difference $=0.7 \mathrm{~mm}$ ). No significant group-by-leg interaction or main effect was found for IR5.

The graphical representation of the relationship between side-to-side differences in sagittal peak knee power absorption/energy absorption and knee laxity is depicted in Fig. 4. No relationship was found between peak knee power absorption and ATD200 (n.s), neither between energy absorbed and ATD200 (n.s). A similar observation was made for the relationship between peak knee power absorption and IR5 (n.s) and energy absorbed and IR5 (n.s).

\section{Discussion}

The most important finding of the present study was that 9 months post-surgery, patients following ACLR showed asymmetry in their knee biomechanics during a bilateral
Fig. 3 Illustration of the devices used for the evaluation of the knee joint laxity. A-leg of a participant on the GNRB for anterior knee joint laxity. B-leg of a participant for rotational knee joint laxity
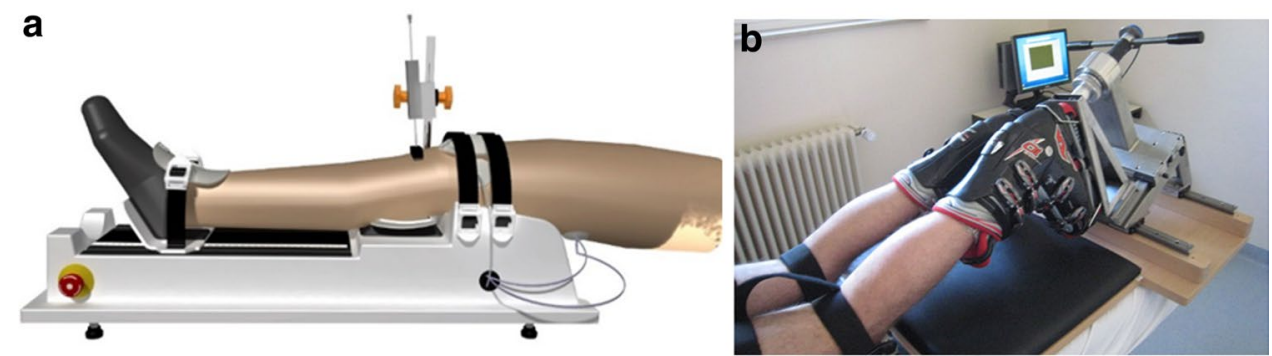
Table 2 Biomechanical variables for controls and patients at both legs during landing from a drop vertical jump

\begin{tabular}{|c|c|c|c|c|c|c|c|}
\hline \multirow[t]{2}{*}{ Variables } & \multicolumn{2}{|c|}{ Controls $(n=28)$} & \multicolumn{2}{|c|}{ ACLR patients $(n=17)$} & \multicolumn{3}{|l|}{$p$-values } \\
\hline & Involved & Non-involved & Involved & Non-involved & Leg effect & Group effect & Leg*group \\
\hline Peak knee power absorption ${ }^{\mathrm{a}}\left(\mathrm{W} \mathrm{kg}^{-1}\right)$ & $15.07( \pm 3.11)$ & $16.31( \pm 2.70)$ & $14.11( \pm 4.15)$ & $17.31( \pm 3.38)$ & 0.003 & n.s & n.s \\
\hline Energy absorbed ${ }^{\mathrm{b}}\left(\mathrm{J} \mathrm{kg}^{-1}\right)$ & $1.49( \pm 0.32)$ & $1.58( \pm 0.27)$ & $1.22( \pm 0.39)$ & $1.62( \pm 0.40)$ & $<0.001$ & n.s & $0.010^{\S, \dagger}$ \\
\hline Knee flexion angle at initial contact $\left(^{\circ}\right)$ & $26.5( \pm 9.5)$ & $27.2( \pm 9.0)$ & $23.4( \pm 8.0)$ & $24.0( \pm 7.0)$ & n.s & n.s & n.s \\
\hline Knee valgus angle at initial contact $\left(^{\circ}\right)$ & $3.3(6.3)$ & $4.5(4.7)$ & $3.7(4.9)$ & $2.0(3.4)$ & n.s & n.s & 0.023 \\
\hline Peak knee flexion angle $\left({ }^{\circ}\right)$ & $101.0( \pm 11.4)$ & $101.7( \pm 11.8)$ & $93.8( \pm 14.9)$ & $96.9( \pm 14.7)$ & 0.019 & n.s & n.s \\
\hline Peak knee valgus angle $\left(^{\circ}\right)$ & $4.6( \pm 6.6)$ & $6.1( \pm 5.0)$ & $6.2( \pm 4.6)$ & $5.3( \pm 4.9)$ & n.s & n.s & n.s \\
\hline Peak knee flexion moment $\left(\mathrm{Nm} \mathrm{kg}^{-1}\right)$ & $1.91( \pm 0.30)$ & $2.03( \pm 0.26)$ & $1.74( \pm 0.35)$ & $2.10( \pm 0.44)$ & 0.001 & n.s & n.s \\
\hline Peak knee valgus moment $\left(\mathrm{Nm} \mathrm{kg}^{-1}\right)$ & $0.06( \pm 0.08)$ & $0.07( \pm 0.08)$ & $0.14( \pm 0.13)$ & $0.17( \pm 0.10)$ & n.s & 0.001 & n.s \\
\hline Peak knee varus moment $\left(\mathrm{Nm} \mathrm{kg}^{-1}\right)$ & $0.36( \pm 0.27)$ & $0.35( \pm 0.17)$ & $0.17( \pm 0.10)$ & $0.19( \pm 0.17)$ & n.s & 0.001 & n.s \\
\hline Peak vertical GRF $(\times B W)$ & $1.67( \pm 0.41)$ & $1.74( \pm 0.46)$ & $1.83( \pm 0.57)$ & $1.87( \pm 0.47)$ & n.s & n.s & n.s \\
\hline ATD200 (mm) & $4.3( \pm 0.8)$ & $4.3( \pm 0.6)$ & $5.6( \pm 1.1)$ & $4.4( \pm 0.8)$ & $<0.001$ & 0.002 & $0.002^{\S, \dagger, \ddagger}$ \\
\hline $\operatorname{IR5}\left({ }^{\circ}\right)$ & $19.24( \pm 5.10)$ & $19.22( \pm 4.50)$ & $20.35( \pm 4.80)$ & $19.48( \pm 4.29)$ & n.s & n.s & n.s \\
\hline
\end{tabular}

Jumps are defined from touch down to maximal knee flexion

$G R F$ ground reaction force, $B W$ body weight, $A T D 200=$ maximal anterior tibial displacement at 200 Newton, IR5 maximal rotational knee laxity at $5 \mathrm{Nm}$

$\S$ Significant difference between $A_{C L R}$ inv and $A C L R_{n-i n v}$

$\dagger$ Significant difference between $\mathrm{ACLR}_{\mathrm{inv}}$ and $\mathrm{CON}_{\mathrm{inv}}$

$¥$ Significant difference between $\operatorname{ACLR}_{n \text {-inv }} / \mathrm{CON}_{n \text {-inv }}$

a Peak knee power absorption in the sagittal plane

${ }^{\mathrm{b}}$ Energy absorbed in the sagittal plane

landing task, which was unrelated to their side-to-side knee joint laxity differences. Our study is the first to compare ACLR patients with healthy control participants regarding both knee landing biomechanics/energetics and static knee joint laxity. While no significant differences were found for peak knee power absorption in the sagittal plane, patients displayed unbalanced knee energy absorption, with a lower performance recorded at their involved leg. The significant group-by-leg interaction and post hoc analyses confirm our hypothesis of greater side-to-side differences in knee landing biomechanics/energetics of ACLR patients compared to controls during bilateral landing. Furthermore, patients had greater anterior knee joint laxity at their involved leg compared to the uninvolved one or the control group, thus confirming our second hypothesis. However, no relationship was found between side-to-side differences in knee landing mechanics and anterior or rotational knee joint laxity, thus infirming our third hypothesis.

Decreased knee work absorption at the involved leg following rehabilitation suggests that ACLR patients tend to reduce the load on the reconstructed knee and to overload the uninvolved leg. This load-shifting strategy is also illustrated in our data of external peak knee flexion moment and power absorption, although the interactions were not significant. These findings corroborate previous research $[25,26,31]$. In a prospective cohort of 10 patients twelve months post-ACLR, Oberländer et al. [25] demonstrated lower sagittal peak knee flexion moments at the involved leg during single-leg landing. They reported a moment redistribution to the adjacent joints, with increased hip flexion and ankle plantarflexion moments. We speculate that our patients adopted a similar moment redistribution strategy during bilateral landing, given that peak GRF was similar in both legs (Table 2). The reason for these landing mechanics could be related to knee extensor muscle strength deficits [25, 31]. Our patients indeed presented with an average quadriceps strength deficit of $12 \%$ (range $1-25 \%$ ), but quadriceps strength was not related to peak knee power absorption, energy absorption or peak knee flexion moment (Pearson's product-moment correlations between -0.35 and 0.42 ; n.s.). Although not tested here, contributing factors of altered knee mechanics may include abnormal muscle activation $[8,24]$ or psychological aspects such as fear of loading or re-injury [3, 20].

Altered sagittal plane knee mechanics during landing might be indicative of increased risk of second ACL injuries or early-onset osteoarthritis, but frontal plane mechanics may also play a role $[15,29]$. Although we found no differences in knee valgus angle between patients and control participants, a main group effect was present for peak knee valgus and varus moments. The greater peak knee valgus moments displayed by our patients could reflect greater valgus loading and higher risk of future injury. However, the values found here were about 5 times 
Side-to-side differences of peak knee power absorption versus side-to-side differences of ATD200

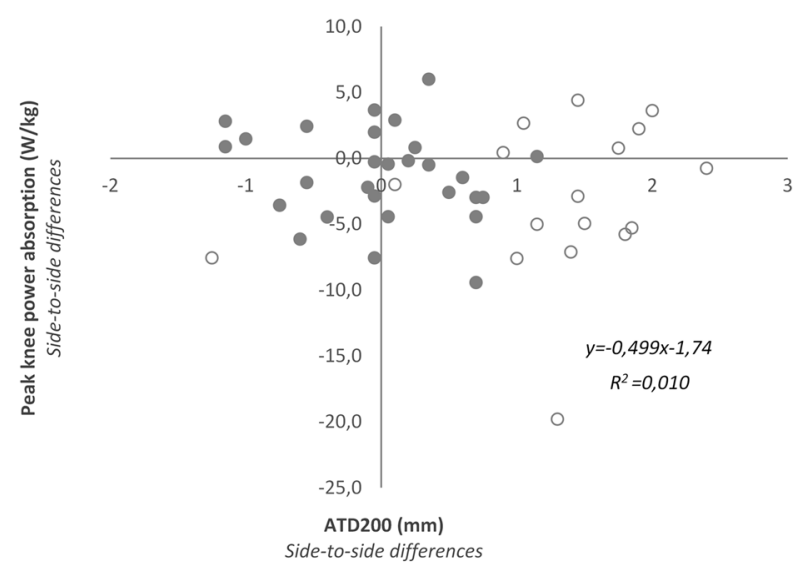

Side-to-side differences of energy absorbed versus side-to-side differences of ATD200

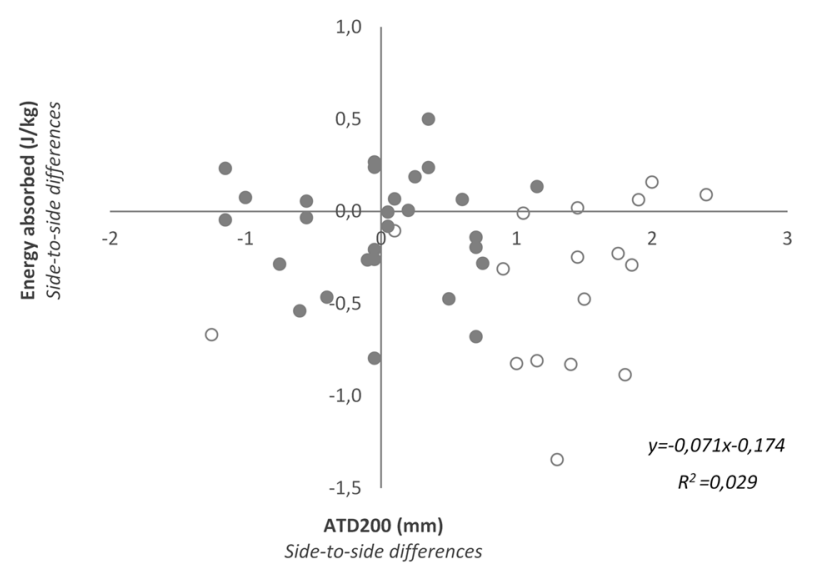

Fig. 4 Scatter diagram displaying the relationship between biomechanical data and knee joint laxity. Scatter diagram displaying the relationship between side-to-side differences of knee joint laxity (abscissa axis) and side-to-side differences of knee power absorption

lower than those from a previous study [15]. In addition, patients globally displayed a reduced peak knee varus moment $\left(0.18 \pm 0.14 \mathrm{Nm} \mathrm{kg}^{-1}\right)$ compared to controls $\left(0.35 \pm 0.22 \mathrm{Nm} \mathrm{kg}^{-1}\right)$. This finding is in line with previous research on gait [37], but contrasts with the suggestion that greater knee external adduction moments could be related to early-onset medial tibiofemoral osteoarthritis [32]. Medial compartment knee osteoarthritis in patients following ACLR might result from other changes in knee mechanics and/or biological/anatomical changes [7, 17].

A previous study reported that ACLR patients displayed increased anterior but not rotational knee joint laxity at their operated leg 27 months following surgery [19]. The group-by-leg interaction, the main group and leg effects for ATD200 and the absence of differences for internal
Side-to-side differences of peak knee power absorption versus side-to-side differences of IR5

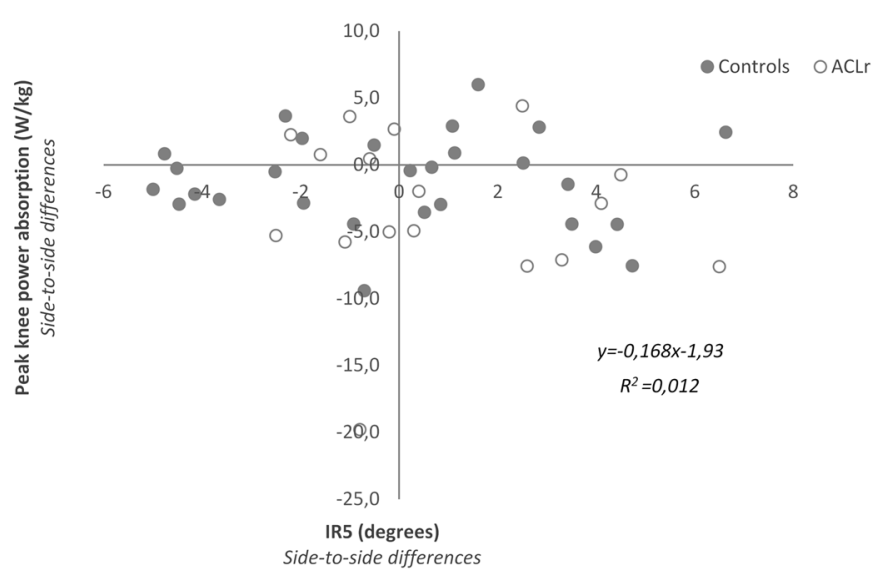

Side-to-side differences of energy absorbed versus side-to-side differences of IR5

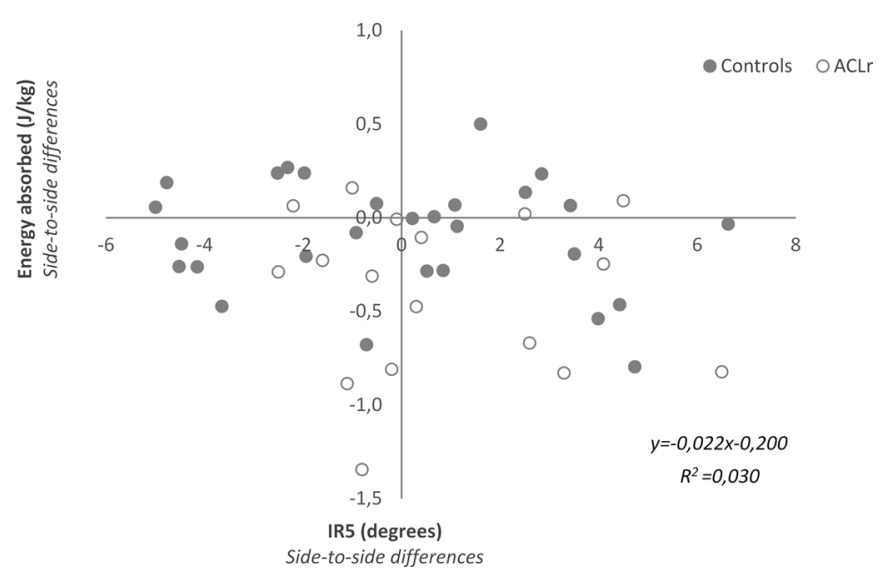

and energy absorption (ordinate axis). ATD200 maximal anterior displacement at $200 \mathrm{~N}, I R 5$ maximal internal rotation at $5 \mathrm{Nm}$. Negative side-to-side differences in power and energy represent decreased values at the operated side

rotational laxity found here support these findings [19]. Our ACLR patients had a $1.3 \mathrm{~mm}$ greater ATD200 at their involved leg compared to their non-involved, which is in accordance with previous research $[11,19]$. Such a side-toside difference might play an important role in subsequent injury risk or further degeneration of the knee joint, as suggested by Myer et al. [23] after screening 1558 athletes for predictors of ACL injury. They reported a fourfold increase in the likelihood of ACL injury for a $1.3 \mathrm{~mm}$ side-to-side difference.

Whether differences in knee laxity are associated with neuromotor control has not been investigated in ACLR patients. A previous study [34] found that in females, but not in males, knee work absorption was positively correlated with knee joint laxity during a bilateral drop jump 
task. However, in our patients, no correlation between peak knee power or energy absorption and ATD200 was found, neither overall, nor in males and females separately (Pearson's product-moment correlations between -0.28 and 0.22 ; n.s.). On the contrary, energy absorbed was $25 \%$ lower, while anterior laxity was $27 \%$ higher in the involved compared to the uninvolved leg. Again this observation holds true for females and males separately. Furthermore, the side-to-side differences in biomechanical variables illustrating this loading shift were unrelated to joint laxity differences (Fig. 4), irrespectively of sex.

One shortcoming of this study is that our focus was exclusively on the knee joint. Thus, we cannot provide a complete picture of the biomechanical compensation strategy adopted by the ACLR patients to unload their involved knee. Insofar, recommendations as to how to restore side-to-side symmetry are limited. Furthermore, our conclusions are based on bilateral landing from a drop jump and may not necessarily hold true for single-leg landing tasks that require greater neuromuscular control. Further study is also warranted regarding the association of knee biomechanics and static knee laxity during other jump tasks, as well as during activities of daily living. Confirmation that there is no relationship between active knee control and static joint laxity would imply that they are independent and complementary characteristics of knee function. In such a case, the sole evaluation of knee joint laxity would not be appropriate to describe knee function under dynamic conditions. Detailed biomechanical analyses should be preferred here to identify abnormal dynamic knee behaviour and form the basis for individualized rehabilitation strategies to be implemented in clinical practice.

\section{Conclusion}

Nine months following surgery, ACLR patients demonstrated side-to-side biomechanical asymmetries in the knee joint in the sagittal, but not the frontal plane. These observations are illustrative of a general unloading strategy at the reconstructed leg. Side-to-side differences were also found in anterior knee laxity measurements, but these were not related to abnormal knee biomechanics during a drop vertical jump. Side-to-side asymmetries in general, and knee unloading in particular, during bilateral tasks as simple as landing from a drop vertical jump may be a risk factor for second ACL injury or early-onset knee osteoarthritis development in ACLR patients. The detection of such strategies bears high clinical relevance for these patients and may thus justify complex biomechanical analyses to be applied in clinical routine.

Acknowledgements This study is part of the ACL-Clinical Pathway Project (Centre Hospitalier de Luxembourg and Luxembourg Institute of Health). The authors would like to thank the following persons involved: Dr Christian Nührenbörger, Prof Dietrich Pape, Dr Alexander Hoffmann, Mrs Hélène Agostinis, the physical therapy team and the research nurse of the Clinique d'Eich. This study has been supported by the Luxembourg Ministry of Sports and the National Olympic Committee.

Author contributions P. Gette, C. Mouton, D. Theisen and R. Seil contributed to conception and design of the study. C.A.G Meyer, P. Gette and C. Mouton collected the data. C.A.G Meyer P. Gette and D. Theisen performed data processing and analysis. C.A.G Meyer, P. Gette, C. Mouton, D. Theisen and R. Seil drafted the article and revised it critically for important intellectual content and were involved in the final approval of the version to be submitted.

\section{Compliance with ethical standards}

Conflict of interests The authors declare that they have no conflict of interest.

Funding This study has been supported by the Luxembourg Ministry of Sports and the National Olympic Committee.

Ethical approval All procedures were approved by the National Research Ethics Committee (CNER, Luxembourg, approval $\left.n^{\circ} 201101 / 05\right)$.

Informed consent Written informed consent was obtained prior to participation.

Open Access This article is distributed under the terms of the Creative Commons Attribution 4.0 International License (http:// creativecommons.org/licenses/by/4.0/), which permits unrestricted use, distribution, and reproduction in any medium, provided you give appropriate credit to the original author(s) and the source, provide a link to the Creative Commons license, and indicate if changes were made.

\section{References}

1. Ahlden M, Kartus J, Ejerhed L, Karlsson J, Sernert N (2009) Knee laxity measurements after anterior cruciate ligament reconstruction, using either bone-patellar-tendon-bone or hamstring tendon autografts, with special emphasis on comparison over time. Knee Surg Sports Traumatol Arthrosc 17:1117-1124

2. Andriacchi TP, Koo S, Scanlan SF (2009) Gait mechanics influence healthy cartilage morphology and osteoarthritis of the knee. J Bone Jt Surg Am 91(Suppl 1):95-101

3. Ardern CL, Osterberg A, Tagesson S, Gauffin H, Webster KE, Kvist J (2014) The impact of psychological readiness to return to sport and recreational activities after anterior cruciate ligament reconstruction. Br J Sports Med 48:1613-1619

4. Baumgart C, Schubert M, Hoppe MW, Gokeler A, Freiwald J (2017) Do ground reaction forces during unilateral and bilateral movements exhibit compensation strategies following ACL reconstruction? Knee Surg Sports Traumatol Arthrosc 25:1385-1394

5. Bizzini M, Gorelick M, Munzinger U, Drobny T (2006) Joint laxity and isokinetic thigh muscle strength characteristics after anterior cruciate ligament reconstruction: bone patellar tendon 
bone versus quadrupled hamstring autografts. Clin J Sport Med 16:4-9

6. Butler RJ, Minick KI, Ferber R, Underwood F (2009) Gait mechanics after ACL reconstruction: implications for the early onset of knee osteoarthritis. Br J Sports Med 43:366-370

7. Chaudhari AM, Briant PL, Bevill SL, Koo S, Andriacchi TP (2008) Knee kinematics, cartilage morphology, and osteoarthritis after ACL injury. Med Sci Sports Exerc 40:215-222

8. Coats-Thomas MS, Miranda DL, Badger GJ, Fleming BC (2013) Effects of ACL reconstruction surgery on muscle activity of the lower limb during a jump-cut maneuver in males and females. J Orthop Res 31:1890-1896

9. Delahunt E, Prendiville A, Sweeney L, Chawke M, Kelleher J, Patterson $\mathrm{M}$ et al (2012) Hip and knee joint kinematics during a diagonal jump landing in anterior cruciate ligament reconstructed females. J Electromyogr Kinesiol 22:598-606

10. Eng JJ, Winter DA (1995) Kinetic analysis of the lower limbs during walking: what information can be gained from a threedimensional model? J Biomech 28:753-758

11. Feller JA, Webster KE (2003) A randomized comparison of patellar tendon and hamstring tendon anterior cruciate ligament reconstruction. Am J Sports Med 31:564-573

12. Hart HF, Culvenor AG, Collins NJ, Ackland DC, Cowan SM, Machotka $\mathrm{Z}$ et al (2016) Knee kinematics and joint moments during gait following anterior cruciate ligament reconstruction: a systematic review and meta-analysis. Br J Sports Med 50:597-612

13. Hefti E, Müller W, Jakob RP, Stäubli HU (1993) Evaluation of knee ligament injuries with the IKDC form. Knee Surg Sports Traumatol Arthrosc 1:226-234

14. Heijne A, Hagstromer M, Werner S (2015) A two- and fiveyear follow-up of clinical outcome after ACL reconstruction using BPTB or hamstring tendon grafts: a prospective intervention outcome study. Knee Surg Sports Traumatol Arthrosc 23:799-807

15. Hewett TE, Myer GD, Ford KR, Heidt RS Jr, Colosimo AJ, McLean SG et al (2005) Biomechanical measures of neuromuscular control and valgus loading of the knee predict anterior cruciate ligament injury risk in female athletes: a prospective study. Am J Sports Med 33:492-501

16. Ithurburn MP, Paterno MV, Ford KR, Hewett TE, Schmitt LC (2015) Young athletes with quadriceps femoris strength asymmetry at return to sport after anterior cruciate ligament reconstruction demonstrate asymmetric single-leg drop-landing mechanics. Am J Sports Med 43:2727-2737

17. Koo S, Rylander JH, Andriacchi TP (2011) Knee joint kinematics during walking influences the spatial cartilage thickness distribution in the knee. J Biomech 44:1405-1409

18. Kristianslund E, Krosshaug T, van den Bogert AJ (2012) Effect of low pass filtering on joint moments from inverse dynamics: implications for injury prevention. J Biomech 45:666-671

19. Lorbach O, Kieb M, Brogard P, Maas S, Pape D, Seil R (2012) Static rotational and sagittal knee laxity measurements after reconstruction of the anterior cruciate ligament. Knee Surg Sports Traumatol Arthrosc 20:844-850

20. Medvecky MJ, Nelson S (2015) Kinesiophobia and return to sports after anterior cruciate ligament reconstruction. Conn Med 79:155-157

21. Mouton C, Seil R, Meyer T, Agostinis H, Theisen D (2015) Combined anterior and rotational laxity measurements allow characterizing personal knee laxity profiles in healthy individuals. Knee Surg Sports Traumatol Arthrosc 23:3571-3577

22. Mouton C, Theisen D, Meyer T, Agostinis H, Nuhrenborger C, Pape D et al (2015) Combined anterior and rotational knee laxity measurements improve the diagnosis of anterior cruciate ligament injuries. Knee Surg Sports Traumatol Arthrosc 23:2859-2867

23. Myer GD, Ford KR, Paterno MV, Nick TG, Hewett TE (2008) The effects of generalized joint laxity on risk of anterior cruciate ligament injury in young female athletes. Am J Sports Med 36:1073-1080

24. Nyland J, Klein S, Caborn DN (2010) Lower extremity compensatory neuromuscular and biomechanical adaptations 2 to 11 years after anterior cruciate ligament reconstruction. Arthroscopy $26: 1212-1225$

25. Oberlander KD, Bruggemann GP, Hoher J, Karamanidis K (2013) Altered landing mechanics in ACL-reconstructed patients. Med Sci Sports Exerc 45:506-513

26. Oberlander KD, Bruggemann GP, Hoher J, Karamanidis K (2014) Knee mechanics during landing in anterior cruciate ligament patients: a longitudinal study from pre- to 12 months postreconstruction. Clin Biomech (Bristol, Avon) 29:512-517

27. Paterno MV, Ford KR, Myer GD, Heyl R, Hewett TE (2007) Limb asymmetries in landing and jumping 2 years following anterior cruciate ligament reconstruction. Clin J Sport Med 17:258-262

28. Paterno MV, Rauh MJ, Schmitt LC, Ford KR, Hewett TE (2012) Incidence of contralateral and ipsilateral anterior cruciate ligament (ACL) injury after primary ACL reconstruction and return to sport. Clin J Sport Med 22:116-121

29. Paterno MV, Schmitt LC, Ford KR, Rauh MJ, Myer GD, Huang B et al (2010) Biomechanical measures during landing and postural stability predict second anterior cruciate ligament injury after anterior cruciate ligament reconstruction and return to sport. Am J Sports Med 38:1968-1978

30. Pollard CD, Stearns KM, Hayes AT, Heiderscheit BC (2015) Altered lower extremity movement variability in female soccer players during side-step cutting after anterior cruciate ligament reconstruction. Am J Sports Med 43:460-465

31. Schmitt LC, Paterno MV, Ford KR, Myer GD, Hewett TE (2015) Strength asymmetry and landing mechanics at return to sport after anterior cruciate ligament reconstruction. Med Sci Sports Exerc 47:1426-1434

32. Sharma L, Hurwitz DE, Thonar EJ, Sum JA, Lenz ME, Dunlop DD et al (1998) Knee adduction moment, serum hyaluronan level, and disease severity in medial tibiofemoral osteoarthritis. Arthritis Rheum 41:1233-1240

33. Shultz SJ, Schmitz RJ (2009) Effects of transverse and frontal plane knee laxity on hip and knee neuromechanics during drop landings. Am J Sports Med 37:1821-1830

34. Shultz SJ, Schmitz RJ, Nguyen AD, Levine BJ (2010) Joint laxity is related to lower extremity energetics during a drop jump landing. Med Sci Sports Exerc 42:771-780

35. Torry MR, Myers C, Pennington WW, Shelburne KB, Krong JP, Giphart JE et al (2011) Relationship of anterior knee laxity to knee translations during drop landings: a bi-plane fluoroscopy study. Knee Surg Sports Traumatol Arthrosc 19:653-662

36. Uhorchak JM, Scoville CR, Williams GN, Arciero RA, St Pierre P, Taylor DC (2003) Risk factors associated with noncontact injury of the anterior cruciate ligament: a prospective four-year evaluation of 859 West Point cadets. Am J Sports Med 31:831-842

37. Webster KE, Feller JA (2012) The knee adduction moment in hamstring and patellar tendon anterior cruciate ligament reconstructed knees. Knee Surg Sports Traumatol Arthrosc 20:2214-2219

38. Willy RW, Bigelow MA, Kolesar A, Willson JD, Thomas JS (2017) Knee contact forces and lower extremity support moments during running in young individuals post-partial meniscectomy. Knee Surg Sports Traumatol Arthrosc 25:115-122 
39. Wright RW, Dunn WR, Amendola A, Andrish JT, Bergfeld J, Kaeding CC et al (2007) Risk of tearing the intact anterior cruciate ligament in the contralateral knee and rupturing the anterior cruciate ligament graft during the first 2 years after anterior cruciate ligament reconstruction: a prospective MOON cohort study. Am J Sports Med 35:1131-1134
40. Zelik KE, Kuo AD (2012) Mechanical work as an indirect measure of subjective costs influencing human movement. PLoS ONE 7:e31143 